\title{
An international comparison of the utilisation of and outcomes from minimal access surgery for the treatment of common abdominal surgical emergencies
}

\author{
Karina Tukanova $^{1} \cdot$ Sheraz R. Markar ${ }^{1}$ [D $\cdot$ Sara Jamel $^{1} \cdot$ Alberto Vidal-Diez $^{1} \cdot$ George B. Hanna $^{1}$
}

Received: 27 March 2019 / Accepted: 22 June 2019 / Published online: 19 August 2019

(c) Springer Science+Business Media, LLC, part of Springer Nature 2019

\begin{abstract}
Background Minimal access surgery (MAS) has suggested improvements in clinical outcomes compared to open surgery in several abdominal elective and emergency surgeries. The aims of this study were to compare England with the United States in the utilisation of MAS and mortality from four common abdominal surgical emergencies.

Methods Between 2006 and 2012, the rate of MAS and in-hospital mortality for appendicitis, incarcerated or strangulated abdominal hernia, small or large bowel and peptic ulcer perforation were compared between England and the United States. Univariate and multivariate analyses were performed to adjust for differences in baseline patient demographics.

Results 132,364 admissions in England were compared to an estimated 1,811,136 admissions in the United States. Minimal access surgery was used less commonly in England for appendicitis (odds ratio (OR) 0.27, 95\% CI 0.267-0.278), abdominal hernia (OR 0.16, 95\% CI 0.15-0.17), small or large bowel perforation (OR 0.33, 95\% CI 0.32-0.35) and peptic ulcer perforation (OR 0.93, 95\% CI 0.87-0.99). In-hospital mortality was increased in England compared to the United States for all four conditions: appendicitis (OR 2.11, 95\% CI 1.66-2.68), abdominal hernia (OR 3.25, 95\% CI 3.10-3.40), small or large bowel perforation (OR 3.88, 95\% CI 3.76-3.99) and peptic ulcer perforation (OR 3.09, 95\% CI 2.94-3.25). In England, after adjustment for patient demographics, open surgery was associated with increased in-hospital mortality for abdominal hernia (OR 1.80, 95\% CI 1.26-2.71), small or large bowel perforation (OR 1.59, 95\% CI 1.37-1.87) and peptic ulcer perforation (OR 2.31, 95\% CI 1.91-2.82).

Conclusions Minimal access surgery was performed less commonly and in-hospital mortality was increased in England compared to the United States for common abdominal surgical conditions. Therefore, strategies to enhance adoption of MAS in emergency conditions in England need to be optimised and include appropriate patient selection and improved surgeon MAS training.
\end{abstract}

Keywords Minimal access surgery $\cdot$ Emergency surgery $\cdot$ Appendicitis $\cdot$ Abdominal hernia $\cdot$ Peptic ulcer perforation · Bowel perforation

Presentation: European Association of Endoscopic Surgery 2019 (Oral presentation).

Electronic supplementary material The online version of this article (https://doi.org/10.1007/s00464-019-06980-y) contains supplementary material, which is available to authorised users.

George B. Hanna

g.hanna@imperial.ac.uk

Sheraz R. Markar

s.markar@imperial.ac.uk

1 Department of Surgery and Cancer, Imperial College London, London, UK
Approximately 35,000 emergency laparotomies are performed in the United Kingdom annually [1]. These emergency cases account for about half of the operative workload in the NHS and carry a high mortality rate, ranging between 15 and $20 \%[2,3]$. Studies assessing variability in survival outcomes following emergency surgery have mainly been focusing on differences in patient characteristics and hospital infrastructure as contributing factors $[4,5]$. No definite guidelines exist in the use of either open or minimal access surgery (MAS), resulting in a great variation in surgical technique amongst different abdominal surgical emergencies. Minimal access surgery has suggested advantages over open surgery in clinical outcomes in the elective setting, 
including enhanced postoperative recovery, minimising blood loss and reducing postoperative pain [6]. Furthermore, several studies demonstrate similar long-term survival between MAS and an open approach for the surgical treatment of abdominal malignant diseases [7-10]. Given these benefits in short-term outcomes in elective surgical cases, MAS has already been implemented in many abdominal surgical domains, largely replacing open surgery in the current era. As MAS can be utilised for both diagnostic and procedural purposes, it plays an important role in the evaluation of acute abdominal pain and also allows immediate surgical management. Nevertheless, abdominal surgical emergencies are predominantly managed with open surgery in the United Kingdom, with only $8 \%$ of the cases completed with MAS according to the National Emergency Laparotomy Audit [11]. The uptake of MAS is highly dependent upon the surgeon's experience with MAS and patient selection to such an approach and specifically their ability to tolerate pneumoperitoneum. Furthermore, the learning curve with MAS can lend itself to an increased operative time, which in an emergency setting may compromise patient clinical outcome. Therefore to date, the effect of MAS on in-hospital mortality still remains unclear for abdominal surgical emergencies specifically.

The aim of this international population-based cohort study was to compare England with the United States for the utilisation of MAS and in-hospital mortality from four common abdominal surgical emergencies (appendicitis, incarcerated or strangulated abdominal hernia, small or large bowel perforation and peptic ulcer perforation) and to evaluate the influence of MAS upon in-hospital and long-term mortality within England.

\section{Materials and methods}

\section{Data sources for hospitalisation, surgical approach and in-hospital mortality}

Frequency data for surgical intervention and in-hospital mortality were obtained using the Hospital Episode Statistics (HES) database for England and the Nationwide Inpatient Sample (NIS) database for the United States. The NIS represents a random $20 \%$ stratified sample of inpatient hospital admissions in the United States. Data were extracted for patients hospitalised for one of the following surgical emergencies: appendicitis, incarcerated or strangulated abdominal hernia, small or large bowel perforation (these were grouped together as it was not possible to distinguish large from small bowel perforation in the USA dataset reliably) and peptic ulcer perforation. Patients of all ages hospitalised for one of these conditions between 1 January 2006 and 31 December 2012 were identified using national codes for emergency type of admission in association with International Classification of Diseases, 10th Revision (ICD10) in HES and International Classification of Diseases, 9th revision, Clinical Modification (ICD-9-CM) diagnosis codes in NIS. The frequency of MAS for each of these surgical emergencies was defined by means of the Office of Population Censuses and Surveys, version 4 (OPCS-4) and the ICD-9-CM procedural codes with the code for MAS. The frequency of cause-specific mortality rates between 2006 and 2012 was obtained from the Office of National Statistics (ONS) for England and the Center for Disease Control and Prevention (CDC) for the United States. The ONS and CDC data cover the same national patient populations as the HES and NIS databases. The Data sources and specification of the codes used in this study are listed in Supplementary Table S1. An IRB approval and written consent were not required as all data are fully anonymised.

\section{Statistical analysis}

\section{Comparison between countries}

Patient demographics for appendicitis, incarcerated or strangulated abdominal hernia, small or large bowel perforation and peptic ulcer perforation were compared between England and the United States (Table 1). Furthermore, both countries were compared using frequency matching. Fiveyear age group, gender, Charlson comorbidity index and year of admission were used to stratify MAS rates. In-hospital mortality was also stratified by the type of surgery. Conditional logistic regression models were fitted and odds ratios comparing England versus the United States were reported (Table 2).

\section{Comparison between surgical operations by country}

For each country, a logistic regression analysis was performed with inverse probability weights based on a propensity score to adjust for confounders that were related to the probability of having MAS and the probability of dying in hospital. Patient demographics (age, gender and deprivation quintile), year of treatment, strategic health authority, teaching hospital status, weekend admission, binary comorbidities and hospital volume quintile were covariates modelling the probability of having MAS. The deprivation quintile (measure of social deprivation) was calculated from the index of multiple deprivation overall rank available in HES, dividing its range (1-32482) in 5 equal categories. A proportional hazard model with inverse probability weights was also performed for England for assessment of the long-term mortality. Inverse probability weights for survey data were also applied for the United States data [12]. Conditional exchangeability was used between patients with MAS and 


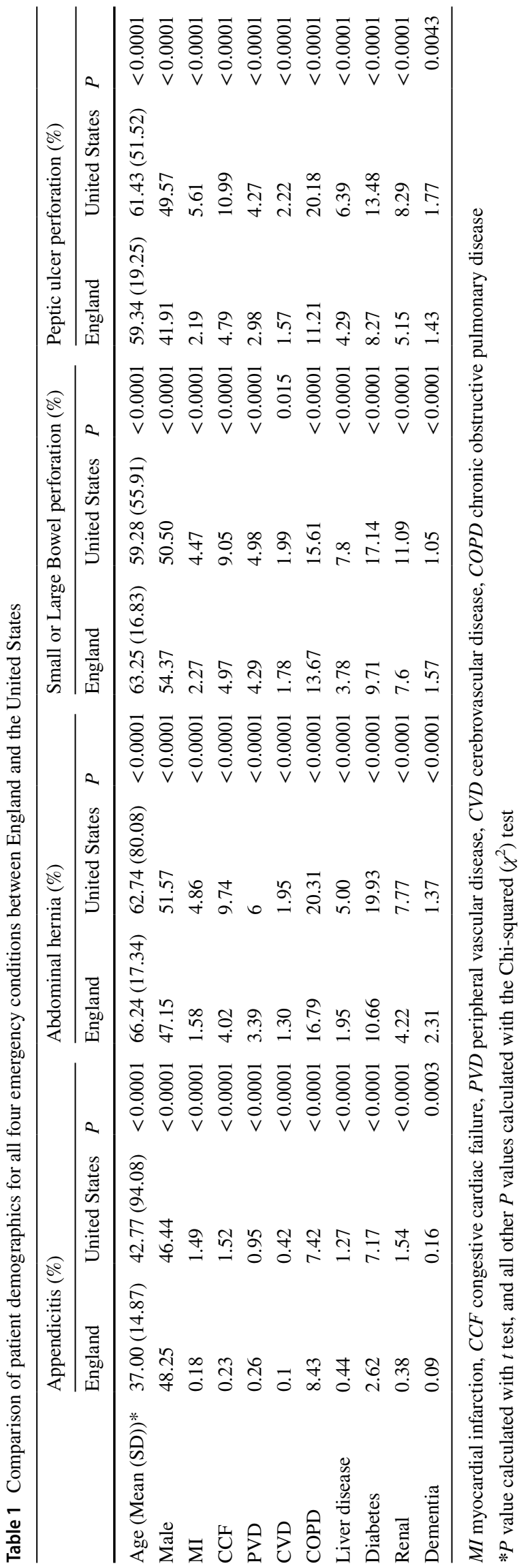

open surgery with respect to the covariate information when modelling the probability of having MAS. Inverse probability weights also assume there is no unknown heterogeneity linked to the treatment and mortality. Absolute differences and relative risks were calculated applying the G-computation formula (Supplementary Table S2) [13]. Long-term out-of-hospital survival data were not available from the NIS dataset and thus long-term mortality was not analysed for the US dataset.

All analyses were performed using SAS version 9.4 (SAS Institute) and R software version 3.5.1 package $\mathrm{r}$.

\section{Results}

\section{Frequency of admission for surgical emergencies}

According to data obtained from the HES database, a total of 132,364 patients were admitted in England for these four abdominal surgical emergencies compared to $1,811,136$ patients in the United States based on the NIS database from 2006 to 2012. Comparison of patient age and medical comorbidities revealed significant differences between England and the United States (Table 1).

\section{Frequency of minimal access surgery}

The rate of MAS for appendicitis, abdominal hernia, small or large bowel perforation and peptic ulcer perforation was $50.68 \%, 2.45 \%, 4.70 \%$ and 8.15\%, respectively, in England. Meanwhile, the frequency of MAS for these conditions was $70.41 \%, 12.97 \%, 9.36 \%$ and $7.72 \%$, respectively, in the United States (Table 2). After standardisation for age, gender, year of admission and Charlson index, MAS was significantly less commonly performed in England in comparison to the United States for all four conditions: appendicitis (OR 0.27, 95\% CI 0.267-0.278), abdominal hernia (OR $0.16,95 \%$ CI $0.15-0.17)$, small or large bowel perforation (OR 0.33, 95\% CI 0.32-0.35) and peptic ulcer perforation (OR 0.93, 95\% CI 0.87-0.99) (Table 2).

\section{In-hospital mortality}

In-hospital mortality in England was 0.1\%, 4.38\%, 17.53\% and $14.77 \%$ for appendicitis, abdominal hernia, small or large bowel perforation and peptic ulcer perforation, respectively. In the United States, the rate of in-hospital mortality for these four surgical emergencies was $0.16 \%, 1.93 \%$, $7.56 \%$ and $8.58 \%$, respectively (Table 2). Following standardisation for age, gender, year of admission, type of surgical intervention and Charlson index, in-hospital mortality was significantly higher in England for all four surgical emergencies compared to the United States: appendicitis (OR 2.11, 
Table 2 Comparison of laparoscopic use and in-hospital mortality for all four emergency gastrointestinal conditions between patients in USA and England

\begin{tabular}{|c|c|c|c|c|}
\hline \multirow[b]{2}{*}{ Factor } & \multicolumn{3}{|l|}{ Univariate analysis } & \multirow{2}{*}{$\begin{array}{l}\text { Multivariate analysis } \\
\text { Odds ratio }(95 \% \mathrm{CI})\end{array}$} \\
\hline & England (\%) & USA (\%) & $P$ value & \\
\hline \multicolumn{5}{|l|}{ Laparoscopic } \\
\hline Appendicitis & $50.68(20881 / 41198)$ & $70.41(877329 / 1245507)$ & $<0.0001$ & $0.27(0.267-0.278)$ \\
\hline Abdominal hernia & $2.45(1076 / 43935)$ & $12.97(47795 / 368399)$ & $<0.0001$ & $0.16(0.15-0.17)$ \\
\hline Small or large bowel perforation & $4.70(1557 / 33150)$ & $9.36(10571 / 112878)$ & $<0.0001$ & $0.33(0.32-0.35)$ \\
\hline Peptic ulcer perforation & $8.15(1148 / 14081)$ & $7.72(6513 / 84352)$ & 0.0764 & $0.93(0.87-0.99)$ \\
\hline \multicolumn{5}{|l|}{ In-hospital mortality } \\
\hline Appendicitis & $0.1(42 / 41192)$ & $0.16(2029 / 1244623)$ & 0.0024 & $2.11(1.66-2.68)$ \\
\hline Abdominal hernia & $4.38(1923 / 43294)$ & $1.93(7122 / 368151)$ & $<0.0001$ & $3.25(3.10-3.40)$ \\
\hline Small or large bowel perforation & $17.53(5808 / 33136)$ & $7.56(8525 / 112794)$ & $<0.0001$ & $3.88(3.76-3.99)$ \\
\hline Peptic ulcer perforation & $14.77(2080 / 14078)$ & $8.58(7232 / 84295)$ & $<0.0001$ & $3.09(2.94-3.25)$ \\
\hline
\end{tabular}

*Adjusted for Age group, gender, type of operation, year of admission and Charlson index

95\% CI 1.66-2.68), abdominal hernia (OR 3.25, 95\% CI 3.10-3.40), small or large bowel perforation (OR 3.88, 95\% CI 3.76-3.99) and peptic ulcer perforation (OR 3.09, 95\% CI 2.94-3.25) (Table 2). This is also illustrated in Fig. 1.

\section{Differences between types of surgery}

Open surgery when compared to MAS was associated with increased in-hospital mortality in England after standardisation for patient demographics for the following three abdominal surgical conditions: abdominal hernia (OR 1.80, 95\% CI 1.26-2.71), small or large bowel perforation (OR 1.59, 95\% CI 1.37-1.87) and peptic ulcer perforation (OR 2.31,
95\% CI 1.91-2.82). Similarly, open surgery was associated with increased long-term mortality for the same conditions: abdominal hernia (HR 1.32, 95\% CI 1.15-1.52), small or large bowel perforation (HR 1.30, 95\% CI 1.18-1.43) and peptic ulcer perforation (HR 1.69, 95\% CI 1.50-1.89) (Table 3).

\section{Length of hospital stay}

The median length of hospital stay (LOS) in England was longer following open surgery compared to MAS for small or large bowel perforation (median LOS of 14 versus 9 days) and peptic ulcer perforation (median LOS of 9

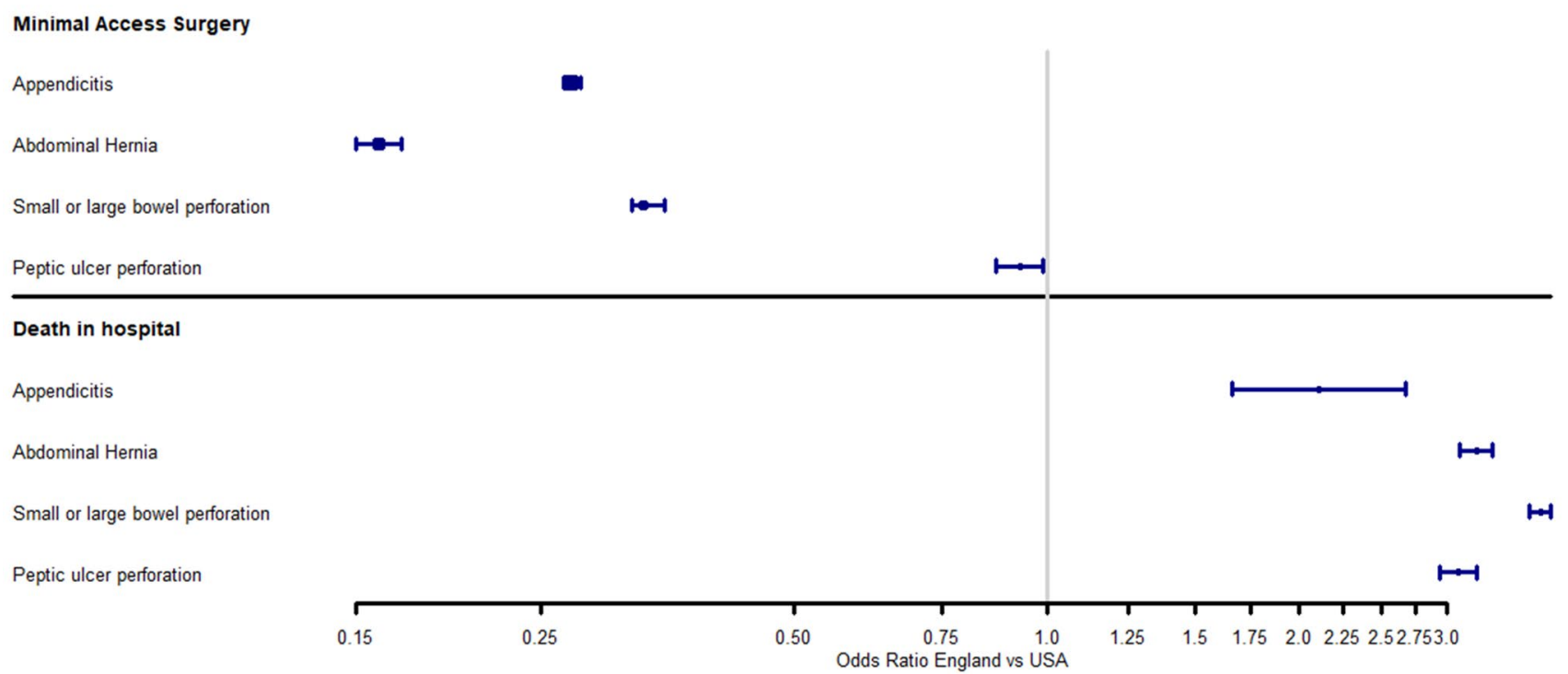

Fig. 1 Odds ratios for the utilisation of minimal access surgery and in-hospital mortality for four abdominal surgical emergency conditions in England and the United States 
Table 3 Comparison between open and laparoscopic surgery using inverse probability weights

\begin{tabular}{lll}
\hline & \multicolumn{2}{l}{ England } \\
\cline { 2 - 3 } Death in-hospital & OR & $95 \%$ CI \\
\hline Appendicitis & 0.91 & $0.53-1.56$ \\
Abdominal hernia & 1.80 & $1.26-2.71$ \\
Small or large bowel perforation & 1.59 & $1.37-1.87$ \\
Peptic ulcer perforation & 2.31 & $1.91-2.82$ \\
\hline Long-term survival & HR & $95 \%$ CI \\
\hline Appendicitis & 0.93 & $0.77-1.13$ \\
Abdominal hernia & 1.32 & $1.15-1.52$ \\
Small or large bowel perforation & 1.30 & $1.18-1.43$ \\
Peptic ulcer perforation & 1.69 & $1.50-1.89$ \\
\hline
\end{tabular}

versus 6 days). Meanwhile, for each condition, the duration of hospital stay was similar in open surgery when compared to MAS in the United States. The latter results were similar to the median LOS of MAS in England for each of the four conditions (Supplementary Table S3).

\section{Discussion}

This population-based study demonstrates that the in-hospital mortality rates were significantly higher for all four abdominal surgical emergencies in England compared to the United States over the 6-year study period. Comparison of the surgical technique for the two countries also showed significant differences for all four conditions, with MAS being less commonly performed in England. Data for long-term survival showed worse prognosis in open surgical intervention for the majority of these abdominal surgical conditions in England. Therefore, this may suggest an association between the surgical technique and in-hospital mortality for these conditions.

Minimal access surgery is associated with both intra- and postoperative clinical benefits compared to open surgery. The incidence of intraoperative blood loss and surgical site infections is significantly lower following MAS [14-16]. Furthermore, MAS reduces the risk for postoperative complications and enhances recovery by decreasing postoperative inflammation and pain, all of which contribute to a reduction in postoperative morbidity and mortality [17-20]. Finally, in concordance with our results for small or large bowel perforation and peptic ulcer perforation, the use of MAS resulted into a decrease in the LOS following emergency surgery [21-24]. Hence, in addition to clinical advantages, a greater implementation of MAS in surgical emergency cases may reduce overall treatment costs mediated through a reduction in the LOS.
The low uptake of MAS in England for surgical emergency cases is likely attributable to a multitude of factors. Utilisation of MAS is highly dependent on the surgeon's expertise. Broader adoption might, however, be limited by technical difficulties associated with MAS including ergonomic challenges, loss of haptic feedback and lack of stereopsis [25, 26]. Hence, a steeper learning curve should be taken into consideration to acquire adequate skills in comparison to open surgery [27, 28]. Although the association between the rate of MAS and volume of surgery is still debated, fewer MAS procedures are performed in lowvolume centres, which may suggest a lack of familiarity or experience with MAS techniques with a low case load [29]. Moreover, differences in early postoperative outcomes are observed when compared to centres implementing MAS more frequently, with a lower incidence of postoperative complications in the latter group [30]. Furthermore, the lack of well-trained staff and the availability and the cost of equipment may further impede more widespread implementation of MAS. In addition, studies in the United States found that patient's education has an influence on their choice of surgical technique such that there was reduced utilisation of MAS in those with lower socio-economic status $[31,32]$. A survey in the United Kingdom assessing challenges in the uptake of MAS found that, although sufficient training opportunities were present, there was a shortage in the funding and time for the adoption of MAS and a rarity of mandatory simulation training sessions for MAS [33]. Finally, to date there is a lack of a large-scale randomised controlled trial confirming the causality of mortality and surgical technique in major abdominal emergency surgery.

Increased implementation of MAS in England for surgical emergency conditions may be achieved by improving access to training and increasing emergency units with high-volume MAS volume. Greater utilisation of MAS will enhance the efficiency of MAS, leading to a reduction in theatre time and a further decrease in the cost effectiveness. This will 
also provide a greater number of suitably trained surgeons, allowing guidance of junior trainees by experienced staff and dissemination of MAS techniques. Lastly, improved patient's education with regard to all available surgical options may expand access to MAS regardless of socio-economic status and enhance the adoption to a larger scale.

Our study was limited by the use of observational administrative datasets for England and the United States. In-hospital mortality was obtained from governmental population-based databases, the CDC and the ONS. The CDC may preclude complete case ascertainment for deaths within 30 days of surgery or deaths following postoperative readmission for the United States. Causal inference techniques were applied to reduce the selection bias but assumptions are also involved in those statistical methods. It was not possible to adjust for confounding by disease severity, nor by case selection based on surgeon's preference using the available databases for both countries. Furthermore, differences in reporting of diagnoses and comorbidities between countries could not be excluded and in-hospital mortality could potentially be biased by a difference in hospital discharge practice.

\section{Conclusions}

In conclusion, the findings in this study suggest that MAS was used less commonly and a greater overall in-hospital mortality in England when compared to the United States was observed for common abdominal surgical conditions. Given the benefits of MAS shown in this large study, strategies to enhance adoption of MAS in emergency conditions in England need to be optimised and include appropriate patient selection and improved surgeon MAS training and experience.

Funding Mr Sheraz Markar is funded by the National Institute of Health Research (NIHR). The views expressed are those of the authors and not necessarily those of the NHS, the NIHR or the Department of Health.

\section{Compliance with ethical standards}

Disclosures Karina Tukanova, Sara Jamel, Dr. Alberto Vidal-Diez, Professor George B. Hanna and Dr. Sheraz R. Markar have no conflicts of interest or financial ties to disclose.

\section{References}

1. Association of Surgeons of Great Britain and Ireland (2012) Emergency General Surgery. ASGBI, London. Accessed 15 Jan 2019

2. RCSEng (2011) Emergency surgery: standards for unscheduled care. Royal College of Surgeons, England. https://www.rcseng.ac. uk/library-and-publications/rcs-publications/docs/emergencysurgery-standards-for-unscheduled-care. Accessed 20 Jan 2019

3. Barrow E, Anderson ID, Varley S, Pichel AC, Peden CJ, Saunders DI, Murray D (2013) Current UK practice in emergency laparotomy. Ann R Coll Surg Engl. https://doi.org/10.1308/003588413x 13629960048433

4. Ozdemir BA, Sinha S, Karthikesalingam A, Poloniecki JD, Pearse RM, Grocott MP, Thompson MM, Holt PJ (2016) Mortality of emergency general surgical patients and associations with hospital structures and processes. Br J Anaesth. https://doi.org/10.1093/ bja/aev372

5. Symons NR, Moorthy K, Almoudaris AM, Bottle A, Aylin P, Vincent CA, Faiz OD (2013) Mortality in high-risk emergency general surgical admissions. Br J Surg. https://doi.org/10.1002/ bjs. 9208

6. Veldkamp R, Kuhry E, Hop WC, Jeekel J, Kazemier G, Bonjer HJ, Haglind E, Påhlman L, Cuesta MA, Msika S, Morino M, Lacy AM (2005) COlon cancer Laparoscopic or Open Resection Study Group (COLOR). Laparoscopic surgery versus open surgery for colon cancer: Short-term outcomes of a randomised trial. Lancet Oncol 1:1-10. https://doi.org/10.1016/s1470-2045(05)70221-7

7. Tapias LF, Mathisen DJ, Wright CD, Wain JC, Gaissert HA, Muniappan A, Lanuti M, Donahue DM, Morse CR (2015) Outcomes with open and minimally invasive ivor lewis esophagectomy after neoadjuvant therapy. Ann Thorac Surg. https://doi. org/10.1016/j.athoracsur.2015.09.062

8. Colon Cancer Laparoscopic or Open Resection Study Group, Buunen M, Veldkamp R, Hop WC, Kuhry E, Jeekel J, Haglind E, Påhlman L, Cuesta MA, Msika S, Morino M, Lacy A, Bonjer HJ (2008) Survival after laparoscopic surgery versus open surgery for colon cancer: long-term outcome of a randomised clinical trial. Lancet Oncol. https://doi.org/10.1016/s1470-2045(08)70310-3

9. Bonjer HJ, Deijen CL, Abis GA, Cuesta MA, van der Pas MH, de Lange-de Klerk ES, Lacy AM, Bemelman WA, Andersson J, Angenete E, Rosenberg J, Fuerst A, Haglind E (2015) COLOR II Study Group. A Randomized Trial of Laparoscopic versus Open Surgery for Rectal Cancer. N Engl J Med. https://doi.org/10.1056/ nejmoa1414882

10. Hu Y, Huang C, Sun Y, Su X, Cao H, Hu J, Xue Y, Suo J, Tao K, He X, Wei H, Ying M, Hu W, Du X, Chen P, Liu H, Zheng C, Liu F, Yu J, Li Z, Zhao G, Chen X, Wang K, Li P, Xing J, Li G (2016) Morbidity and mortality of laparoscopic versus open D2 Distal gastrectomy for advanced gastric cancer : a randomized controlled trial. J Clin Oncol. https://doi.org/10.1200/jco.2015.63.7215

11. NELA Project Team (2011) Fourth Patient Report of the National Emergency Laparotomy Audit RCoA London. Accessed 2 Feb 2019

12. Ridgeway G, Kovalchik SA, Griffin BA, Kabeto MU (2015) Propensity score analysis with survey weighted data. J. Causal Infer. https://doi.org/10.1515/jci-2014-0039

13. Austin PC (2009) Absolute risk reductions, relative risks, relative risk reductions, and numbers needed to treat can be obtained from a logistic regression model. J Clin Epidemiol. https://doi. org/10.1016/j.jclinepi.2008.11.004

14. Meynaud-Kraemer L, Colin C, Vergnon P, Barth X (1999) Wound infection in open versus laparoscopic appendectomy: a meta-analysis. Int J Technol Assess Health Care 15(2):380-391

15. Richards C, Edwards J, Culver D et al (2003) Does using a laparoscopic approach to cholecystectomy decrease the risk of surgical site infection? Ann Surg. https://doi.org/10.1097/01.sla.00000 $55221.50062 .7 \mathrm{a}$

16. Ng SS, Lee JF, Yiu RY, Li JC, Leung WW, Leung KL (2008) Emergency laparoscopic-assisted versus open right hemicolectomy for obstructing right-sided colonic carcinoma: a comparative study of short-term clinical outcomes. World J Surg 32:454-458. https://doi.org/10.1007/s00268-007-9400-0 
17. Bhogal RH, Athwal R, Durkin D, Deakin M, Cheruvu CN (2008) Comparison between open and laparoscopic repair of perforated peptic ulcer disease. World J Surg. https://doi.org/10.1007/s0026 8-008-9707-5

18. Biondi A, Di Stefano C, Ferrara F, Bellia A, Vacante M, Piazza L (2016) Laparoscopic versus open appendectomy: a retrospective cohort study assessing outcomes and cost-effectiveness. World J Emerg Surg. https://doi.org/10.1186/s13017-016-0102-5

19. Southgate E, Vousden N, Karthikesalingam A, Markar SR, Black S, Zaidi A (2012) Laparoscopic vs open appendectomy in older patients. Arch Surg 147:557-562. https://doi.org/10.1001/archs urg.2012.568

20. Wei HB, Huang JL, Zheng ZH, Wei B, Zheng F, Qiu WS, Guo WP, Chen TF, Wang TB (2010) Laparoscopic versus open appendectomy: a prospective randomized comparison. Surg Endosc 24:266-269. https://doi.org/10.1007/s00464-009-0563-7

21. Fowkes L, Krishna K, Menon A, Greenslade GL, Dixon AR (2008) Laparoscopic emergency and elective surgery for ulcerative colitis. Colorectal Dis 10(4):373-378. https://doi.org/10.111 1/j.1463-1318.2007.01321.x

22. Bleier JI, Moon V, Feingold D, Whelan RL, Arnell T, Sonoda T et al (2008) Initial repair of iatrogenic colon perforation using laparoscopic methods. Surg Endosc 22:646-649. https://doi. org/10.1007/s00464-007-9429-z

23. Stulberg JJ, Champagne BJ, Fan Z, Horan M, Obias V, Marderstein E et al (2009) Emergency laparoscopic colectomy: does it measure up to open? Am J Surg 197:296-301. https://doi. org/10.1016/j.amjsurg.2008.09.010

24. Marcello PW, Milsom JW, Wong SK, Brady K, Goormastic M, Fazio VW (2001) Laparoscopic total colectomy for acute colitis: a case-control study. Dis Colon Rectum 44:1441-1445. https:// doi.org/10.1007/BF02234595

25. Harada H, Kanaji S, Nishi M, Otake Y, Hasegawa H, Yamamoto M, Matsuda Y, Yamashita K, Matsuda T, Oshikiri T, Sumi Y, Nakamura T, Suzuki S, Sato Y, Kakeji Y (2017) The learning effect of using stereoscopic vision in the early phase of laparoscopic surgical training for novices. Surg Endosc. https://doi. org/10.1007/s00464-017-5654-2

26. Bloch E, Uddin N, Gannon L, Rantell K, Jain S (2014) The effects of absence of stereopsis on performance of a simulated surgical task in two-dimensional and three-dimensional viewing conditions. Br J Ophthalmol. https://doi.org/10.1136/bjophthalm ol-2013-304517

27. Vickers AJ, Savage CJ, Hruza M, Tuerk I, Koenig P, MartínezPiñeiro L, Janetschek G, Guillonneau B (2009) The surgical learning curve for laparoscopic radical prostatectomy: a retrospective cohort study. Lancet Oncol. https://doi.org/10.1016/ s1470-2045(09)70079-8

28. Tekkis PP, Senagore AJ, Delaney CP, Fazio VW (2005) Evaluation of the learning curve in laparoscopic colorectal surgery: comparison of right-sided and left-sided resections. Ann Surg 242(1):83-91

29. Hawkins AT, Ford MM, Hopkins MB, Muldoon RL, Wanderer JP, Parikh AA, Geiger TM (2018) Barriers to laparoscopic colon resection for cancer: a national analysis. Surg Endosc. https://doi. org/10.1007/s00464-017-5782-8

30. Kim MG, Kwon SJ (2014) Comparison of the outcomes for laparoscopic gastrectomy performed by the same surgeon between a low-volume hospital and a high-volume center. Surg Endosc. https ://doi.org/10.1007/s00464-013-3352-2

31. Cooper MA, Hutfless S, Segev DL, Ibrahim A, Lyu H, Makary MA (2014) Hospital level under-utilization of minimally invasive surgery in the United States: retrospective review. BMJ. https:// doi.org/10.1136/bmj.g4198

32. Hawkins AT, Ford MM, Benjamin Hopkins M, Muldoon RL, Wanderer JP, Parikh AA, Geiger TM (2017) Barriers to laparoscopic colon resection for cancer: a national analysis. Surg Endosc. https://doi.org/10.1007/s00464-017-5782-8

33. Cole A, O’Neill P, Sampson C, Lorgelly P (2018) Barriers to uptake of minimal access surgery in the United Kingdom. Ohe consulting report, London: office of health economics. https:// www.ohe.org/publications/barriers-uptake-minimal-access-surge ry-united-kingdom. Accessed 1 Mar 2019

Publisher's Note Springer Nature remains neutral with regard to jurisdictional claims in published maps and institutional affiliations. 